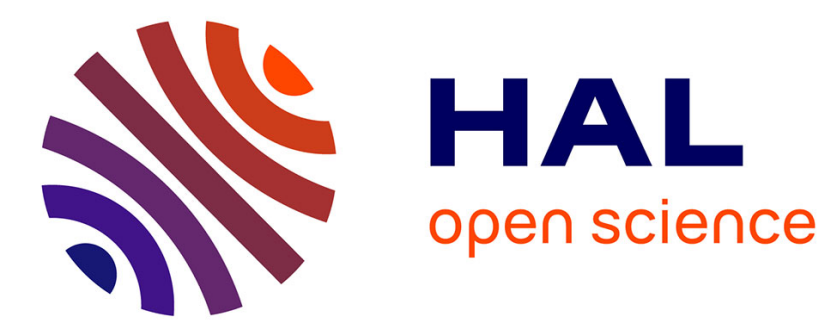

\title{
Playing with Empathy Through a Collaborative Storytelling Game
}

\author{
Sindre B. Skaraas, Javier Gomez, Letizia Jaccheri
}

\section{To cite this version:}

Sindre B. Skaraas, Javier Gomez, Letizia Jaccheri. Playing with Empathy Through a Collaborative Storytelling Game. 17th International Conference on Entertainment Computing (ICEC), Sep 2018, Poznan, Poland. pp.254-259, 10.1007/978-3-319-99426-0_26 . hal-02128638

\section{HAL Id: hal-02128638 \\ https://hal.inria.fr/hal-02128638}

Submitted on 14 May 2019

HAL is a multi-disciplinary open access archive for the deposit and dissemination of scientific research documents, whether they are published or not. The documents may come from teaching and research institutions in France or abroad, or from public or private research centers.
L'archive ouverte pluridisciplinaire HAL, est destinée au dépôt et à la diffusion de documents scientifiques de niveau recherche, publiés ou non, émanant des établissements d'enseignement et de recherche français ou étrangers, des laboratoires publics ou privés. 


\title{
Playing with Empathy through a Collaborative Storytelling Game
}

\author{
Sindre B. Skaraas, Javier Gomez, and Letizia Jaccheri \\ Department of Computer Science, NTNU, Trondheim, Norway \\ sibsen@live.com, \{javier.escribano, letizia.jaccheri\}@ntnu.no
}

\begin{abstract}
This study follows the early stages of a serious educational game about empathy. By having players collaborate on telling a story, it aims to exercise their empathic abilities. Each player uses a smartphone which displays the story structure and grants new cues for building the story together. This study shows the exploratory phase aimed at proving the game concept and identifying points to be further developed. The game was evaluated in a workshop trial with 12 participants. This evaluation showed enough potential to warrant development into a more focused version that facilitates empathic responses.
\end{abstract}

Keywords: Serious Games, Affective Learning, Empathy, Collaborative Storytelling.

\section{Introduction}

One of the most common qualifiers to measure how we deal with the world is empathy. As children will grow up, their opinions and perspectives will be formed largely based on their ability to understand other people's motives, emotions and views. Storytelling is a natural and reoccurring way for humans to develop empathy [18]. In fact, novels are one of the main forms of communication cultures have had to share different perspectives and to build empathy in their population. Despite this, the role of empathy in video games is a topic that has often received more negative attention than positive $[1,10]$. This project aims to provide an activity that will positively affect empathy by emulating a storytelling and story creation experience. This activity will consist of a group of people that will collaborate on telling a story. By making each player understand and add to the story, they are forced to put themselves into the story and to have an empathic response to the character [16]. This is done in a way of collaborative learning, which is found to be more interesting to the players and to promote critical thinking [9]. The development is directed by certain guidelines for educational games, as presented by Annetta [2], to make sure the users can achieve heightened engagement and affective learning.

The game is presented in [17]. The research question is whether such a relation exists between the game experience and the players' empathy. The game uses storytelling as a way to exercise the ability to form an empathic understanding to an imagined situation. The players then show that they can interpret the 
story, build on it, and explain it to the group. In this stage, the study takes an informal approach. The aim is to explore the possibilities of the game with a real audience and to gather feedback to take the concept further. So because of that preliminary form, the game study exists mainly as a proof-of-concept. It is a combination of a digital system and a real-world activity of oral storytelling. The digital aspect is simply a conduit that provides communication tools and a structure to the play. The "game" in its true sense is determined when the players interact with each other and decide how they will develop the story. Because of this reliance on the group dynamic, there is an element of uncertainty to the game design. This is why the study also takes an exploratory approach, seeking the aid of the players to further develop the prototype.

The study reported in this paper is part of a larger ecosystem of projects. This ecosystem is formed under the novel of "The Little Doormaid: Tappetina" [13]. This novel also lends its name to the game in this study. Starting as a way to interpret the story of the novel into a digital game, this project has since evolved into a collaborative storytelling platform. The ecosystem is an initiative to encourage nuanced views of people. It is formed under to combat the stigma that surrounds women entering male-associated fields such as technology.

The structure of this paper is as follows: Section 2 will look at a collection of works that serves as background for this research project. Section 3 outlines the evaluation process and discussion of its results. And section 4 then talks about how the game will be developed for improvement and more focused research.

\section{State of the Art}

There has been a fair amount of studies that set out to prove the effectiveness of game-based learning. Smiley [19] suggests how the research field is now beyond simply asking if game-based learning can be effective. The author shows how several application areas exist where instructional games are proven to be more effective than ordinary instruction, something echoed by a more recent literature overview by Susi et al. [3]. So instead, Van Eck [19] argues studies should look more at why they are effective, and how - which is to say, "when, with whom, and under what conditions". This is where the core motivation for this research proposal lies - to further explore how the to-be developed game can drive learning. Key to the research is uncovering the landscape of ideas that seems promising and that are grounded in theory. Regarding the educational content games may have, there is again the literature overview by Connoly et al. [8]. Here, they analyze different (positive) impacts of games, which include different learning outcomes such as: affective learning, knowledge acquisition, perceptual/cognitive skills and behavior change.

Since a narrative is central to the game development of this project, it would be useful to find how stories are related to games in general. The basis for that discussion is found in an article by Jenkins [14] that clears up the question of what the role between games and narrative really is. The work connects games and movies in that game narratives are not linear nor essential thing in games as 
it is in cinema. It's also showed here how the game designers are not storytellers, but "narrative architects". This is because their real role is creating game spaces that facilitate narrative experiences, or spatial stories. Four approaches to such environmental storytelling is suggested: (1) making spaces that evoke narratives the player is already familiar with, (2) enacting the narrative at certain spots of the game, (3) revealing the plot by embedding bits of info in the environment, and (4) letting narratives emerge spontaneously within the game. This fourth approach is what lead to coming up with the concept of the game activity in this study.

In [1], Anderson et. al describes how much research has been dedicated to make a link between violent video games and decreased pro-social behavior. Recently, more research has been going in the opposite direction, to investigate the positive effect of games on empathy. So-called pro-social games are shown by Greitemeyer et al. in [10] to increase empathy along with a reduction in being pleased at someone else's misfortune, or schadenfreude. Greitemeyer et al. then shows support for the positive aspects of the General Learning Model (GLM) of Buckley et al. [5]. The GLM is an generalized version of the General Aggression Model (GAM), which was solely used to just look at the negative effects of violent games. With the GLM, games are portrayed as a media that when exposed to, one's mental state can be affected, leading to possible reactions in behavior. In [4], Belman et al. makes an overview of different efforts to promote empathy in social sciences, and recommends how to extend these studies to creating "games for good" that try to promote certain ethical values. Of note, two dimensions are identified in these studies. Firstly, Dispositional vs Induced Empathy, where studies may look behavior affected by empathy vs how empathy can itself be changed. The second dimension is Low- vs High-Involvement. In a game, this would determine how much the player is immersed in terms of time, engagement and building relationships in a player community.

As for popular entertainment games, there exists those that use different forms of storytelling and empathy in their mechanics: An older game genre that features collaborative storytelling is tabletop role-playing games, such as Dungeons and Dragons [11]. In this game, the story is created by a central narrator as each players take on a character and role dice to determine results. Other games will have all players contribute equally to creating the story, such as Once Upon a Time [15] by Atlas Games, which combines fairy tales and more traditional, competitive card playing. These games and others serve as inspiration to design the digital game and associated activity. Empathy games, on the other hand, take several forms: Some may deal with exploring one's identity (Who Am I? Race Awareness Game [12]) or to simulate social interaction (Hall of Heroes [6] - helps teens adapt to middle school). Games that combine storytelling and empathy do so often by teaching problem-solving (Four Little Corners - An interactive storybook app about friendship [7]), but may be too inflated to be properly studied in terms of the exact relationship to empathy. This space is where this game wishes to fill. By simplifying the story structure, it may give the players the reins to exercise their empathic abilities. 


\section{Evaluation}

Since the study at this stage was determined to not require a formal experiment, the methodology was loose and not very controlled. So, instead of formal data collection, it was deemed that having a researcher heavily involved in and observing the activity would grant the most insight. This way the feasibility can be evaluated by interacting with participants. This gives rise to investigating feedback and examining what points need improvement. The main form of getting feedback was observation and note-taking. The researcher played the game together with the participants. This means that while taking part in the story building, he could talk to the players and get an insight into how well they engage with the game. Since the researcher participated in the game, it was not a blind trial. The participants were to be informed of the goals of the game and given some guidance on how to play, when needed. Data collection methods included recording audio of the activity, a short questionnaire, plus the game data: the complete constructed story and their individual solutions. The data results allowed one to look back on the trial and effectively reconstruct the interaction and story building process.

The evaluation was held during the workshop "Games, culture and science for boys and girls". This event took place at the Gunnerus Library (Trondheim, Norway). It was conducted by NTNU researchers and aimed at teenagers. The objective of the workshop was to introduce teenagers to research and the current games developed at the University. Having this workshop as the context of the evaluation made it less of a typically controlled research environment. Instead, everyone was open to comment, share their experience, and play however they liked. "Tappetina's Empathy" was among several games to be presented here. Around 30 people in total were present to play the games. Teenagers were also brought in to help organize the activities as well as participate themselves. This lead to a relaxed and jovial atmosphere, which was further contributed to by encouraging the participants to pick the games they wanted to try out. Before the activities, each game project got to present their goal and agenda, informing everyone about what the game would be like. The first batch of players would be pre-determined, followed by a period of walking around to the games that each found interesting. In addition to the game trials, there were art installations and brief history lessons, as this was a hosted in an old library.

Because of the number of workshops and time constraints, only 12 players played the game activity in groups of 4 people. Most of them were teens of age 13 or older, some joined by their parents. Their point of initiative was mixed between being lead to the game by the organizers and electing to play this game over others after hearing the presentation. Similarly to the other games, "Tappetina's Empathy" received its own isolated room for the players to sit in a circle. Here, the players could speak and focus without distractions.

Among the data points observed is engagement. That is, how much fun the experience was for the players. Looking at the questionnaire data, there were varying amounts of engagement: When asked how much they enjoyed playing the game, most players answered 4 out of 5 stars. Going by the observations and 
the audio recording, players displayed different emotional reactions and level of focus. A couple of younger kids were naturally more boisterous with friends or siblings present, showing great willingness to build onto the story with numerous details. Others were reserved and silent, but could eventually offer a constructive story addition.

Players had also different ways of interacting with the story and the game tools. The most timid could at times do nothing but repeat the cue they selected. The majority of participants showed an innate ability to use their fantasy to build onto the story. Some would even put elements of their own life into the character and story, displaying a desire to form real-world, empathetic connections to the fiction. Players showed differences in their comprehension of the game structure. This can be interpreted through time spent selecting and how they expressed that the choices were difficult. There did seem to be a hint of relation between this comprehension and the player's age and self-rated empathy. When it comes to the correlation to empathy, some hints were gathered about a possible relationship here. In the question form, the players were asked to rate their empathy ability.Looking at all the answers for this, and comparing them to their respective answers for enjoyment,we see a 0.73 average distance. While this is hardly enough for a proof in its own terms, it does grant an indication that further research can look at. To be adapted, the game's design would need to focus even more on requiring the player to form an emotional understanding to succeed and have fun. As it is, there is not enough agency in the player's hands to properly shape the story. This may be because of a overly simplistic structure, or that the Story Tag events themselves are too descriptive.

\section{Taking the Game Further}

The trial was considered enough of a success that the game is to be further developed. The overall response from the players was positive, who were intrigued by the concept. A couple players even showed a desire to download the game and play it with their friends. The main goal was however to determine if it could be used to make a stronger connection to empathy. This was also determined to be fulfilled enough to warrant a more focused approach. Finally, some improvements and changes would be in order to better influence or be influenced by empathic abilities.

\section{Acknowledgment}

This work has been partially supported by NTNU ARTEC and by the ERCIM fellowship program. The authors would like to thank Alexandra Angeletaki for organizing the international experiment workshop at the Gunnerus library of NTNU. The project has been recommended by the Data Protection Official for Research, Norwegian Social Science Data Services (NSD). For the development 
of the game, the Unity Engine and editor was utilized, as developed by Unity Technologies.

\section{References}

1. Anderson, C.A., Shibuya, A., Ihori, N., Swing, E.L., Bushman, B.J., Sakamoto, A., Rothstein, H.R., Saleem, M.: Violent video game effects on aggression, empathy, and prosocial behavior in eastern and western countries: A meta-analytic review. Psychological bulletin 136(2), 151 (2010)

2. Annetta, L.A.: The "I's" have it: A framework for serious educational game design. Review of General Psychology 14(2), 105 (2010)

3. Backlund, P., Hendrix, M.: Educational games-are they worth the effort? a literature survey of the effectiveness of serious games. In: Games and virtual worlds for serious applications (VS-GAMES), 2013 5th international conference on. pp. 1-8. IEEE (2013)

4. Belman, J., Flanagan, M.: Designing games to foster empathy. International Journal of Cognitive Technology 15(1), 11 (2010)

5. Buckley, K.E., Anderson, C.A.: A theoretical model of the effects and consequences of playing video games. Book: Playing Video Games: Motives, Responses, and Consequences pp. 363-378 (2006)

6. Centervention: Hall of Heroes game (2016)

7. Company, D.: Four Little Corners - An interactive storybook app about friendship (2013)

8. Connolly, T.M., Boyle, E.A., MacArthur, E., Hainey, T., Boyle, J.M.: A systematic literature review of empirical evidence on computer games and serious games. Computers \& Education 59(2), 661-686 (2012)

9. Gokhale, A.A.: Collaborative learning enhances critical thinking. Journal of Technology Education 7(1) (1995)

10. Greitemeyer, T., Osswald, S., Brauer, M.: Playing prosocial video games increases empathy and decreases schadenfreude. Emotion 10(6), 796 (2010)

11. Gygax, G., Arneson, D.: Dungeons and Dragons, vol. 19. Tactical Studies Rules Lake Geneva, WI (1974)

12. Interactive, P.: Who Am I? Race Awareness Game (2010)

13. Jaccheri, L.: The Little Doormaid: Tappetina. CreateSpace Independent Publishing Platform (2016)

14. Jenkins, H.: Game design as narrative. Computer 44, 53 (2004)

15. Lamber, R., Rilstone, A., Wallis, J.: Once Upon a Time: The Storytelling Card Game (2003)

16. Manney, P.J.: Empathy in the time of technology: How storytelling is the key to empathy. Journal of Evolution and Technology 19(1), 51-61 (2008)

17. Skaraas, S.B., Gomez, J., Jaccheri, L.: Tappetina's empathy game: A playground of storytelling and emotional understanding. In: Proceedings of the 17th ACM Conference on Interaction Design and Children. pp. 509-512. IDC '18 (2018)

18. Smiley, J.: Thirteen ways of looking at the novel. Alfred a Knopf Incorporated (2005)

19. Van Eck, R.: Digital game-based learning: It's not just the digital natives who are restless. EDUCAUSE review 41(2), 16 (2006) 